\section{Race and Gender Differences in Undergraduate Research Mentoring Structures and Research Outcomes}

\author{
Melissa L. Aikens, ${ }^{\dagger}$ Melissa M. Robertson, ${ }^{+}$Sona Sadselia, ${ }^{\S}$ Keiana Watkins, ${ }^{\S}$ \\ Mara Evans," Christopher R. Runyon," Lillian T. Eby, ${ }^{*}$ and Erin L. Dolan ${ }^{\$ *}$ \\ 'Department of Biological Sciences, University of New Hampshire, Durham, NH 03824; ”Department \\ of Psychology and \$Department of Biochemistry \& Molecular Biology, University of Georgia, \\ Athens, GA 30602; "Department of Biology, University of North Carolina at Chapel Hill, Chapel Hill, \\ NC 27599; 'Department of Educational Psychology, University of Texas at Austin, Austin, TX 78712
}

\begin{abstract}
Participating in undergraduate research with mentorship from faculty may be particularly important for ensuring the persistence of women and minority students in science. Yet many life science undergraduates at research universities are mentored by graduate or postdoctoral researchers (i.e., postgraduates). We surveyed a national sample of undergraduate life science researchers about the mentoring structure of their research experiences and the outcomes they realized from participating in research. We observed two common mentoring structures: an open triad with undergraduate-postgraduate and postgraduate-faculty ties but no undergraduate-faculty tie, and a closed triad with ties among all three members. We found that men and underrepresented minority (URM) students are significantly more likely to report a direct tie to their faculty mentors (closed triad) than women, white, and Asian students. We also determined that mentoring structure was associated with differences in student outcomes. Women's mentoring structures were associated with their lower scientific identity, lower intentions to pursue a science, technology, engineering, and mathematics (STEM) PhD, and lower scholarly productivity. URM students' mentoring structures were associated with higher scientific identity, greater intentions to pursue a STEM PhD, and higher scholarly productivity. Asian students reported lower scientific identity and intentions to pursue a STEM PhD, which were unrelated to their mentoring structures.
\end{abstract}

\section{INTRODUCTION}

Undergraduate research, during which students conduct research projects in faculty members' laboratories, has been championed as a way to decrease the gap in the number of women and underrepresented minority (URM) students in science (National Academy of Sciences, National Academy of Engineering, and Institute of Medicine, 2011). Participation in undergraduate research can retain underrepresented students in science majors (Barlow and Villarejo, 2004; Hurtado et al., 2009; Jones et al., 2010; Espinosa, 2011) and influence students' decisions to pursue postgraduate education or a research career in science (Hathaway et al., 2002; Villarejo et al., 2008; Carter et al., 2009; Schultz et al., 2011; Harsh et al., 2012). More proximally, students who participate in research report gains in their abilities to think and work like a scientist (Seymour et al., 2004; Hunter et al., 2007), self-efficacy in science research (Chemers et al., 2011; Robnett et al., 2015), and identity as scientists (Hunter et al., 2007; Adedokun et al., 2012; Robnett et al., 2015), which are indicators of student growth as scientists and can be predictors of students' pursuit of science research-related careers (Estrada et al., 2011).

How undergraduate researchers are mentored influences the extent to which they realize these outcomes, because mentors provide guidance, information, and support that help undergraduates become integrated into their disciplines (Aikens et al., 2016).
Jose Herrera, Monitoring Editor Submitted August 7, 2016; Revised February 9, 2017; Accepted February 16, 2017

CBE Life Sci Educ June 1, 2017 16:ar34 DOI:10.1187/cbe.16-07-0211

*Address correspondence to: Erin L. Dolan (eldolan@uga.edu).

(c) 2017 M. L. Aikens et al. CBE-Life Sciences Education @ 2017 The American Society for Cell Biology. This article is distributed by The American Society for Cell Biology under license from the author(s). Two months after publication it is available to the public under an Attribution-Noncommercial-Share Alike 3.0 Unported Creative Commons License (http://creativecommons.org/ licenses/by-nc-sa/3.0).

"ASCB®" and "The American Society for Cell Biology $\circledR^{\prime \prime}$ are registered trademarks of The American Society for Cell Biology. 


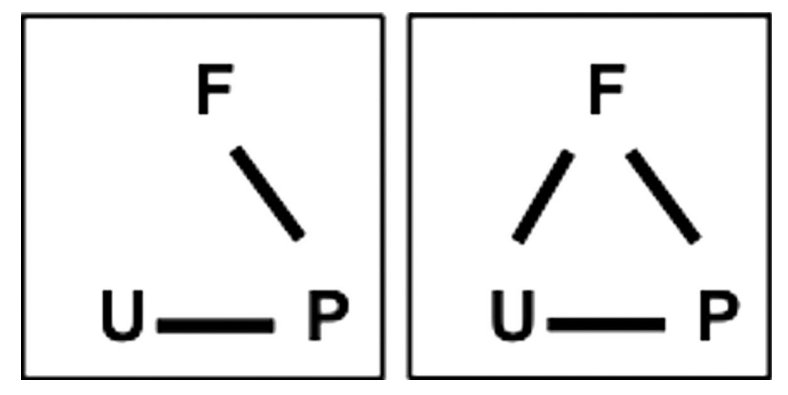

FIGURE 1. The two common mentoring triads in undergraduate research experiences. The open triad is on the left, and the closed triad is on the right. $F$, faculty member; $P$, postgraduate; $U$, undergraduate researcher.

In addition, faculty mentors can serve as role models and make connections that help students pursue graduate study or a science career (Ovink and Veazey, 2011; Thiry and Laursen, 2011). Faculty mentors may be particularly important for the persistence of women and URM students in science, because these students generally have fewer science role models (lower representation of women and URMs among science faculty, in science texts, etc.) and more limited networks within the scientific community than white men (Nelson and Rogers, 2003; Towns, 2010). Yet many undergraduate researchers at research universities are not mentored directly by faculty. They are often mentored by graduate students or postdoctoral associates (collectively referred to as a "postgraduates"; Dolan and Johnson, 2010), who themselves are mentored by faculty. This creates a mentoring triad structure, of which there are two common forms (Figure 1): an open triad with undergraduate-postgraduate and postgraduate-faculty relationships, or ties, but no undergraduate-faculty tie, and a closed triad with ties among all three members (Aikens et al., 2016).

Closed triads are characterized by a direct interaction between the undergraduate and the faculty member. This direct connection may be important for students' development of a scientific identity, because recognition from established members of the scientific community influences scientific identity (Carlone and Johnson, 2007; Hurtado et al., 2011; Aikens et al., 2016). In closed triads, everyone interacts, which can promote trust (Granovetter, 1985; Coleman, 1988; Burt, 2000, 2001). Enhanced trust may prompt mentors to give undergraduates more advanced tasks and grant them more autonomy in the lab, which could enhance undergraduates' development of scientific knowledge and skills, science self-efficacy, and scientific identity (e.g., Seymour et al., 2004). In fact, undergraduate researchers in closed triads consistently report more positive cognitive, affective, and behavioral outcomes than undergraduate researchers in open triads (Aikens et al., 2016). However, little research has examined whether students of different gender, racial, or ethnic identities (i.e., sociodemographics) differ in the outcomes they realize from research. Determining whether undergraduate researchers' outcomes differ based on their sociodemographics and whether their mentoring structures explain these differences is important for understanding whether and how undergraduate research experiences and research mentoring may level the playing field or create inequities between underserved science students and their majority counterparts.
Social network theory offers a useful framework for thinking about the nature of undergraduate research mentoring structures, specifically whether the undergraduate perceives the undergraduate-faculty tie being present versus absent (closed vs. open triad, respectively). Granovetter (1973) posited that ties could not only be present or absent, but also weak versus strong, and that the strength of a tie is a combination of the amount of time spent in the relationship, the emotional intensity of the relationship, the intimacy of the relationship (e.g., confiding in one another), and the extent to which the relationship offers reciprocal benefits (e.g., doing things for one another). Marsden and Campbell (1984) empirically distinguished two of these dimensions of tie strength: time spent in a relationship and depth or emotional closeness. Thus, we sought to understand whether the frequency with which undergraduate researchers interacted with faculty mentors and the closeness they felt in the relationship could explain whether they reported being in an open versus closed mentoring triad.

Many studies have found differences in the frequency of interactions and closeness of students' relationships with faculty based on the students' gender, race, or ethnicity (Kuh and Hu, 2001; Lundberg and Schreiner, 2004; Chang, 2005; Sax et al., 2005; Zhao et al., 2005; Kim and Sax, 2009; Kim et al., 2009; Kim and Lundberg, 2016; Hurtado et al., 2011; Fuentes et al., 2014). For example, Asian students interact less and have fewer positive interactions with faculty than other student groups (Kuh and Hu, 2001; Chang, 2005; Kim et al., 2009). Studies of the experiences of women of all racial and ethnic backgrounds and of African-American students (both men and women) are more equivocal. Some studies have found that women and African-American students interact with faculty more than their majority counterparts (Kuh and $\mathrm{Hu}, 2001$; Lundberg and Schreiner, 2004; Chang, 2005; Sax et al., 2005; Fuentes et al., 2014), and others have found these students interact with faculty less than their majority counterparts (Hurtado et al., 2011; Kim and Lundberg, 2016). Few of these studies have examined student-faculty interactions specifically in science, technology, engineering, and mathematics (STEM) fields (but see Zhao et al., 2005; Hurtado et al., 2011), which may be unique because of the cultural stereotypes associated with science.

Differences in student-faculty interactions by gender may result from the stereotyping of science as a male domain. Gender stereotypes of science are posited to arise due to the incongruity between the expected roles of women in society and the expected roles of scientists in society (Eagly and Karau, 2002). Women are perceived as having communal attributes, such as being nurturing, helpful, selfless, and gentle, whereas men are perceived as having agentic attributes, such as being assertive, dominant, independent, and self-confident (Eagly, 1987), which align more closely with the perceived attributes of a science career and reflect majority cultural norms and stereotypes (Diekman et al., 2010). These stereotypes persist even among scientists working in scientific fields with high proportions of women (Smyth and Nosek, 2015).

Stereotypes about the academic competence of traditionally marginalized racial and ethnic groups also put these students at risk of discrimination. URM undergraduate and graduate students in science report feeling perceived by faculty and peers as less intellectually capable than white students (Carlone and Johnson, 2007; Hurtado et al., 2009; Griffin et al., 2015), and 
this has the potential to influence the quantity or quality of interactions with a faculty mentor. Asian students, on the other hand, are stereotyped as high achievers, especially in math and science. Although this "model minority" stereotype may seem benign, it can have negative implications (Cheryan and Bodenhausen, 2000). For example, faculty may interact less with Asian students if they assume that Asian students are competent at science. Conversely, Asian students may find it difficult to ask faculty mentors for help, because help seeking defies the model minority stereotype, suggesting they are somehow inadequate (Museus and Park, 2015).

We sought to address three research questions. First, we asked whether a student's gender ${ }^{1}$ or race/ethnicity was associated with his/her likelihood of directly interacting with the faculty mentor. Specifically, we tested whether women versus men are more likely to experience open or closed mentoring triads. We also tested whether Asian ${ }^{2}$ students or URM students versus white students were more likely to experience open or closed mentoring triads. Second, we asked, if students experience different triads based on their sociodemographics, can this difference be explained by how frequently the undergraduate and faculty member interact or the closeness of their relationship? To address this, we examined whether frequency of interaction or relationship closeness mediated the relationship between a student's gender or race/ethnicity and his/her membership in a closed versus open triad. Finally, we asked whether students' gender or race/ethnicity was associated with their research outcomes in ways that could be explained by their triad membership. In other words, does triad membership mediate any observed relationships between students' sociodemographics and the outcomes they realize from participating in research? We focused on three outcomes that directly relate to student persistence in science: 1) scientific identity, which has been shown to predict students' intentions to pursue a science research-related career (Estrada et al., 2011); 2) students' scholarly productivity, which is likely to influence their admission into STEM PhD programs; and 3) students' intentions to enroll in a STEM PhD program, because undergraduate research experiences are viewed as critical for clarifying whether to pursue a doctoral degree.

\section{METHODS}

\section{Participants}

We surveyed undergraduate researchers in the life sciences at research universities across the United States about their research experiences, as described in Aikens et al. (2016). Participants had to have completed at least one summer or semester of undergraduate research in the life sciences in the past 2 years and had to have worked with a postgraduate during the research experience. We primarily recruited undergraduates by sending survey invitations through university- or department-maintained listservs of undergraduate researchers.

${ }^{1}$ We acknowledge that gender is a spectrum, but the population in our study primarily identified as males and females.

${ }^{2}$ We recognize that students who identify as Asian have a spectrum of experiences and more careful disaggregation by specific cultural or national identity is needed to understand these experiences. In this study, we made use of the broad category of "Asian." This pooling may mask patterns distinct to each particular population, but gives us information on patterns shared across groups identifying as Asian.
We also sent invitations to listservs of students who participated in National Science Foundation (NSF) Research Experiences for Undergraduates programs, and we recruited students at the Society for the Advancement of Chicanos and Native Americans in Science and the Association of Biomedical Researchers Conference for Minority Students conferences. We offered a \$20 incentive to undergraduates to complete the survey. This study was approved by institutional review boards at the University of Georgia (2013-10391) and the University of Texas at Austin (2014-06-0094).

A total of 842 eligible undergraduates completed the survey, representing more than 50 research universities from across the United States. Students reported their gender as male, female, or other. Only two students identified as "other"; we did not include their responses in the study due to sample size concerns. We used separate items for race and ethnicity on the survey. Students could identify with multiple races: American Indian or Alaska Native, African American, Asian, Native Hawaiian or other Pacific Islander, white, or Other. For ethnicity, students could identify as Hispanic or Latino/a or not Hispanic or Latino/a. The number of responses from American Indian/Alaskan Native, African American, Native Hawaiian/Pacific Islander, and Hispanic/Latino/a students was relatively low. We recognize there are differences between these student groups, but due to sample size restraints, we made the decision to combine them into a single URM category. This pooling may mask patterns distinct to each particular population but broadly gives us information on patterns shared across these groups. Seven students chose "other" for their race/ ethnicity; their responses were not included in the analyses due to small sample size. We focus the analysis presented here on students who reported being in the open or closed triads depicted in Figure 1, since these triads are the most commonly observed, accounting for $83 \%$ of all responses $(n=699$; Aikens et al., 2016). In all, these decisions reduced the eligible sample size to 680 undergraduates (Table 1).

Although we did not intend for this study to examine the effects of gender, racial, or ethnic matches between undergraduate researchers and their faculty mentors, we were able to collect gender, race, and ethnicity data from a subset of faculty mentors $(n=293)$. With respect to gender, 172 identified as male $(\sim 59 \%)$, 119 identified as female ( $41 \%)$, and two preferred not to respond. With respect to race and ethnicity, 235 identified as white $(\sim 80 \%), 31$ identified as Asian $(\sim 11 \%), 19$ identified as URM $(\sim 7 \%)$, and four preferred not to respond. We cannot

TABLE 1. Characteristics of the undergraduates used in the analyses: overall and by triad type $(n=680)$

\begin{tabular}{lccc}
\hline & \multicolumn{2}{c}{ Open triad } & \multicolumn{2}{c}{ Closed triad } \\
Characteristics & Total & & \\
\hline Gender & & & \\
$\quad$ Male & $245(36 \%)$ & 68 & 177 \\
Female & $435(64 \%)$ & 169 & 266 \\
Race/ethnicity & & & \\
White & $320(47 \%)$ & 111 & 209 \\
Asian & $222(33 \%)$ & 94 & 128 \\
URM & $138(20 \%)$ & 32 & 106 \\
\hline
\end{tabular}


assume that responding faculty represent the larger pool of faculty who mentored the 680 undergraduates in our sample, but we report these data here as context for interpreting our results.

\section{Measures}

Mentoring Triad Type. We presented a diagram of eight triad types to each student as described in Aikens et al. (2016) and asked each one to indicate which triad best represented his/her relationship with the postgraduate and faculty member with whom he/she worked (see the Supplemental Material). Only students who reported participating in the triads depicted in Figure 1 were included in the analyses. The open triad was coded 0 , and the closed triad was coded 1 .

Frequency of Interaction with Faculty Mentor. We queried undergraduates about how often, on average, they interacted with their faculty mentors. The response options were: several times a day, daily, weekly, monthly, less than once a month, and other. "Other" responses were recoded as missing in the analyses.

Rapport with Faculty Mentor. Given the dearth of tools useful for measuring the closeness of the relationships between undergraduate researchers and their research mentors, we turned to work done at the graduate level to characterize advisor-advisee relationships. In their efforts to examine mentoring at the graduate level, Schlosser and Gelso (2001) developed the Advisory Working Alliance Inventory (AWAI) as a measure of the working relationship between graduate students and their faculty advisors. Schlosser and Gelso (2001) describe the working alliance in advisory relationships as the "portion of the relationship characterized by the cooperation, mutuality, and collaboration in regard to the work being conducted" reflecting the "connection between advisor and advisee that is made during work toward common goals" (p. 158). Because we were interested specifically in closeness of the undergraduate-faculty relationship, we used the Rapport subscale of the AWAI (Schlosser and Gelso, 2001) to measure students' perceptions of their rapport with their faculty mentors. Students responded on a scale of 1 to 5 (strongly disagree to strongly agree) to 11 items that measure rapport, including "This individual offered me encouragement," "I do not think that this individual believed in my ability to succeed in science (reverse scored)," "This individual welcomed my input into our discussions," and "I felt uncomfortable working with this individual (reverse scored)." The full set of items is provided in the Supplemental Material. This scale showed high internal consistency with our student sample ( $n=606$, Cronbach's $\alpha=$ 0.887). For each student, a rapport score was calculated by taking the mean of the rapport items. See the Supplemental Material for additional information about the rapport scale.
Scientific Identity. We used the five-item Scientific Identity scale (Estrada et al., 2011) to measure a student's scientific identity. Students responded on a scale of 1 to 5 (strongly disagree to strongly agree) to items including "I have a strong sense of belonging to the community of scientists," "I feel like I belong in the field of science," and "The daily work of a scientist is appealing to me." The full set of items is provided in the Supplemental Material. This scale showed high internal consistency ( $n=655$, $\alpha=0.860$ ). For each student, a scientific identity score was calculated by taking the mean of the scientific identity items.

Scholarly Productivity. We calculated a scholarly productivity score as described in Aikens et al. (2016). Students indicated the number of times $(0-5+)$ they had completed the following activities as result of their research experiences: "presented a poster or talk as part of a local program or event," "presented a poster at a regional, national, or international conference," "presented a talk at a regional, national, or international conference," "participated in writing a manuscript for publication in a peer-reviewed journal," and "published an article in a peer-reviewed journal." We used these data to create a scholarly productivity score for each student, ranging from less to more influential: $0=$ no scholarly productivity; $1=$ presented at a local event; 2 = presented at a regional, national, or international conference; or 3 = coauthored a manuscript. A student's score indicated the highest level of scholarly productivity achieved but did not account for the number of times he/she was involved in creating any particular scholarly product.

Intentions to Enroll in PhD Program in STEM. We used one item from the Undergraduate Research Student Self-Assessment instrument (Hunter et al., 2009; Weston and Laursen, 2015) to examine whether the research experience influenced students' intentions to pursue a PhD in a STEM discipline. We asked students how likely they were to enroll in a $\mathrm{PhD}$ program in science, mathematics, or engineering after their research experiences compared with their intentions before doing research. Student responses ranged from 1 to 5 (not more likely to extremely more likely).

Means and medians for all mediator and dependent variables are presented in Table 2. All items and response options can be found in Table S1 in the Supplemental Material. Correlations for all variables used in these analyses can be found in Table S2 in the Supplemental Material.

\section{Data Analyses}

We tested one direct model (Figure 2) and two path models (Figures 3 and 4) in Mplus, version 7.4. A direct logistic regression model was used to test whether gender and race/ethnicity

TABLE 2. Means $( \pm S D)$ or medians for each mediator and dependent variable by gender and race/ethnicity

\begin{tabular}{lccccc}
\hline & Male & Female & White & URM & Asian \\
\hline Frequency of interaction & $3.10(0.99)$ & $2.86(0.99)$ & $2.92(0.96)$ & $3.22(1.08)$ & $2.83(0.96)$ \\
Rapport & $4.36(0.56)$ & $4.28(0.62)$ & $4.34(0.61)$ & $4.40(0.64)$ & $4.22(0.55)$ \\
Scientific identity & $4.14(0.72)$ & $4.04(0.75)$ & $4.12(0.75)$ & $4.25(0.71)$ & $3.92(0.71)$ \\
Scholarly productivity & 2 & 1 & 1 & 2 & 2 \\
Intentions to pursue a STEM PhD & 3 & 3 & 3 & 4 & 2 \\
\hline
\end{tabular}

a Means are provided for continuous variables (frequency of interaction, rapport, and scientific identity; range: 1-5). Medians are provided for ordinal variables (scholarly productivity [range: $0-3$ ] and intentions to pursue a STEM PhD [range: 1-5]). 


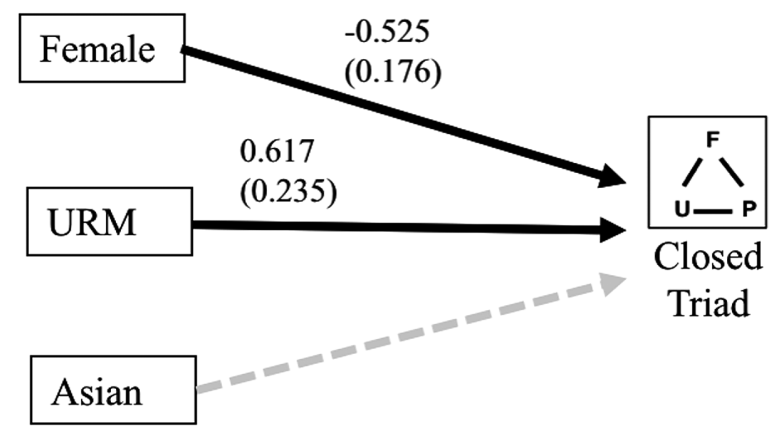

FIGURE 2. Direct model showing all pathways tested (solid black and dotted gray lines). The regression coefficient ( \pm SE) for each significant pathway (solid black lines) is shown. Female $\rightarrow$ closed triad $p=0.003$; URM $\rightarrow$ closed triad $p=0.009$.

predicted membership in the open versus closed triad. We used three independent variables related to gender and race/ethnicity: gender (male/female), URM (yes/no), and Asian (yes/no). The reference group for gender was male and for race/ethnicity was white. Both gender and race/ethnicity variables were included in the same model so that we could obtain estimates of the effect of gender on triad membership, controlling for race/ethnicity, and the effects of race/ethnicity on triad membership, controlling for gender. Mplus uses an underlying continuous latent-response variable approach when estimating $R^{2}$ for categorical variables. $R^{2}$ represents the variance explained by the latent-response variable underlying the categorical variable (Snijders and Bosker, 1999; www.statmodel.com/ download/techappen.pdf). We used maximum-likelihood (ML) estimation to obtain regression coefficients. ML is used to obtain unbiased estimates of parameters when dependent variables are binary or ordinal.

Although there may be other variables that covary with the sociodemographic variables examined (e.g., socioeconomic status, grade point average, first-generation status), there is converging evidence that control variables should be used with caution (Spector and Brannick, 2011; Bernerth and Aguinis,

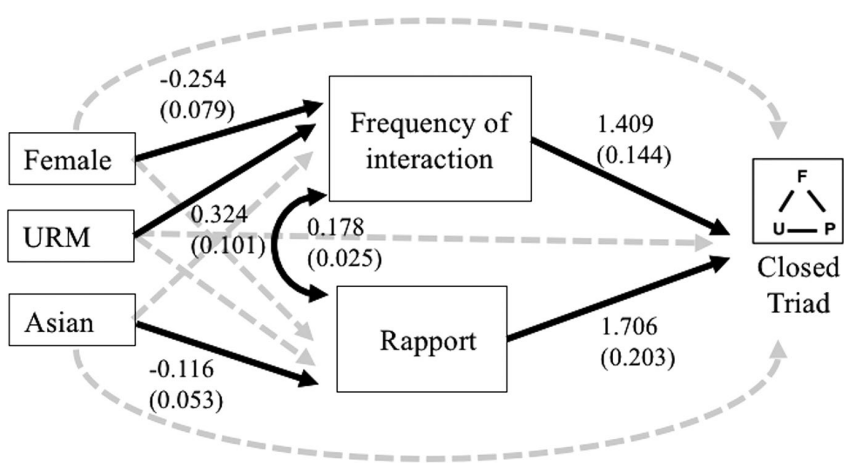

FIGURE 3. Path model 1 showing all pathways tested (solid black and dotted gray lines). The regression coefficient $( \pm S E$ ) for each significant pathway (solid black lines) is shown. Female $\rightarrow$ frequency of interaction $p=0.001$; URM $\rightarrow$ frequency of interaction $p=0.001$; Asian $\rightarrow$ rapport $p=0.028$; frequency of interaction $\leftrightarrow$ rapport $p=0.000$; frequency of interaction $\rightarrow$ closed triad $p=0.000$; rapport $\rightarrow$ closed triad $p=0.000$.
2016). The "purification principle" (Spector and Brannick, 2011 , p. 288) that underlies the rationale often used to justify the inclusion of control variables has been seriously questioned on both theoretical and empirical grounds (Spector and Brannick, 2011; Bernerth and Aguinis, 2016), and current best practice is "when in doubt, leave them out" (Becker et al., 2016, p. 158).

Path models represent systems of regression equations that allow for examination of both direct and indirect effects of one or more independent variables on one or more dependent variables. We estimated path coefficients (i.e., regression coefficients) using ML estimation and Monte Carlo integration. ML estimation was used because the model contained binary (e.g., triad) and ordinal (e.g., scholarly productivity, intentions to pursue a STEM $\mathrm{PhD}$ ) dependent variables. Monte Carlo integration is a form of numerical integration used to estimate indirect effects when there are missing data on the mediators. Although there were very few missing data on the mediators (i.e., more than $95 \%$ of the included participants had nonmissing values), Monte Carlo integration allowed us to follow the best practice of using all available data to estimate parameters (e.g., Newman, 2014).

In the first path model (Figure 3), we tested the effects of gender and race/ethnicity (female, URM, Asian) on triad membership through two mediators (frequency of interaction and rapport). Frequency of interaction was normally distributed, so we treated it as a continuous variable; a subsequent analysis using frequency of interaction as an ordinal variable did not change the results. We allowed the error terms for the two mediators to covary to account for the association between frequency of interaction and rapport, and direct paths from the demographic variables to triad membership were included. Indirect effects are calculated as the product of the regression coefficients that comprise the pathway from the independent variable to the mediator $\left(b_{\mathrm{mx}}\right)$ and from the mediator to the dependent variable $\left(b_{\mathrm{ym}}\right)$. Indirect effects for this model were specified using the model indirect feature in Mplus, which uses the delta method (MacKinnon, 2008) to test the product of the $b_{\mathrm{mx}}$ and $b_{\mathrm{ym}}$ coefficients for significance.

In the second path model (Figure 4), we tested the effects of the demographic variables on three outcomes (scientific identity, scholarly productivity, and intentions to pursue a STEM PhD) through a binary mediator (triad membership). Direct effects from the demographic variables to the outcomes were included. Scholarly productivity and intention to pursue a STEM PhD were treated as ordinal variables in the analyses. Results from the Brant Wald test for proportional odds indicated that the associations between the independent variables and the ordinal variables did not differ across the levels of the ordinal variables $\left(\chi_{\text {Productivity }}^{2}(6)=9.678, p=0.139 ; \chi_{\text {Intention }}^{2}(9)=\right.$ 9.791, $p=0.368$ ). These results indicated that ordinal logistic models were appropriate for estimating the hypothesized associations in this study. Indirect effects were calculated using formulas provided by Iacobucci (2012) for models with categorical mediators and outcomes.

\section{RESULTS}

We first examined the direct model (Figure 2) to determine whether students differed in their triad membership according to their sociodemographics. We found significant differences in students' triad membership depending on their gender and 


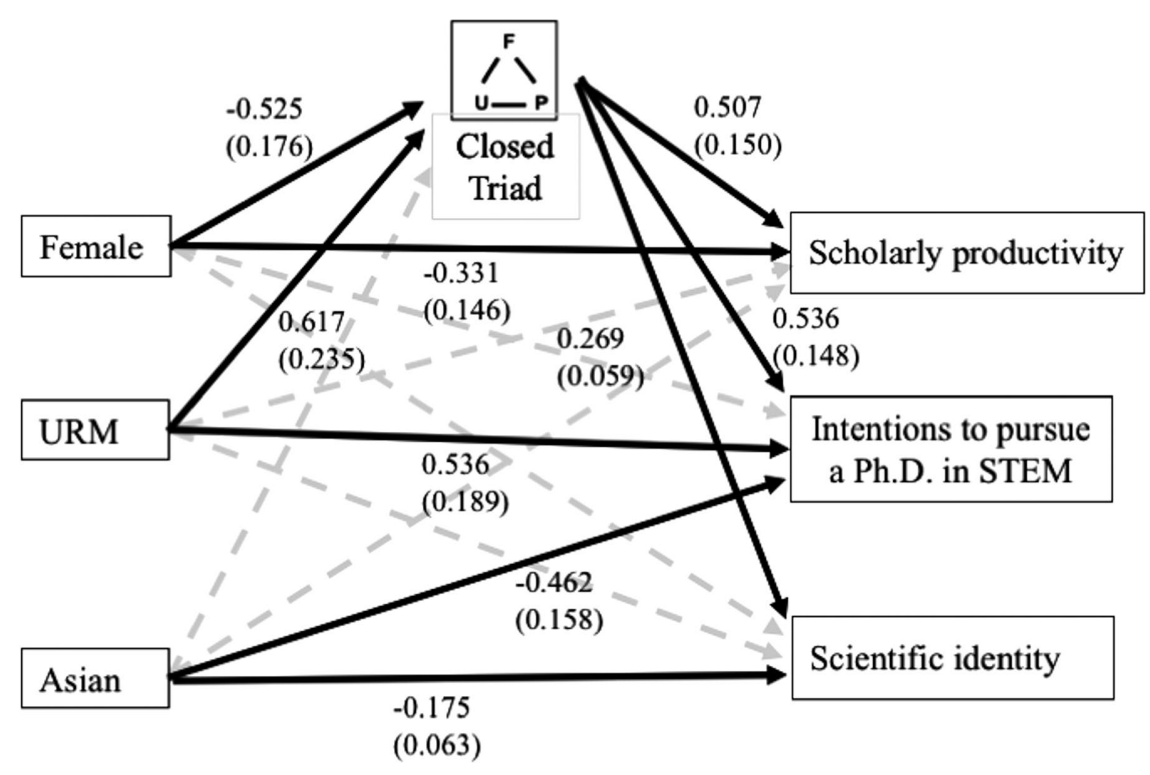

FIGURE 4. Path model 2 showing all pathways tested (solid black and dotted gray lines). The regression coefficient ( \pm SE) for each significant pathway (solid black lines) is shown. Female $\rightarrow$ closed triad $p=0.003$ and scholarly productivity $p=0.023$; URM $\rightarrow$ closed triad $p=0.009$ and intentions to pursue a PhD in STEM $p=0.005$; Asian $\rightarrow$ intentions to pursue a PhD in STEM $p=0.003$ and scientific identity $p=0.005$; closed triad $\rightarrow$ scholarly productivity $p=0.001$, intentions to pursue a PhD in STEM $p=0.000$, and scientific identity $p=0.000$.

race/ethnicity (Figure 2 and Table 3). However, the three demographic variables together accounted for only $4.8 \%$ of the variance in triad membership. When we controlled for race/ ethnicity, men were $\sim 1.7$ times more likely than women to be in the closed triad than in the open triad. Similarly, after we controlled for gender, URM students were $~ 1.9$ times more likely than white students to be in the closed triad than in the open triad. Asian students did not significantly differ from white students in their triad membership.

We then examined the indirect model (Figure 3) to determine whether the frequency with which students interacted with their faculty mentors or their rapport with their faculty mentors mediated the observed sociodemographic differences in the odds of being in a closed versus open triad. Together, the sociodemographic variables, frequency of interaction, and rapport accounted for $56.4 \%$ of the variance in triad membership.

TABLE 3. Logistic regression results for direct effect model ${ }^{\mathrm{a}}$

\begin{tabular}{lccc}
\hline $\begin{array}{l}\text { Intercept }( \pm \text { SE) } \\
\text { Independent variable }\end{array}$ & $\boldsymbol{b}( \pm$ SE) & $\boldsymbol{p}$ Value & $\mathrm{e}^{b}$ \\
\hline Gender & & & \\
$\quad$ Female & $-0.525(0.176)$ & 0.003 & 0.592 \\
Race/ethnicity & & & \\
$\quad$ Asian & $-0.294(0.181)$ & 0.104 & 0.745 \\
$\quad$ URM & $0.617(0.235)$ & 0.009 & 1.853 \\
$R^{2}$ & 0.048 & & \\
\hline
\end{tabular}

aThe odds of being in the closed triad relative to the open triad was calculated as $\mathrm{e}^{b}$. Odds ratios $<1$ indicate less likelihood of being in the closed triad than the open triad, and odds ratios $>1$ indicate greater likelihood of being in the closed triad than the open triad.
Greater frequency of interaction and greater rapport significantly increased the odds that a student indicated he/she was in a closed triad. Gender and race/ethnicity explained only $3.5 \%$ of the variance in frequency of interaction and $1.7 \%$ of the variance in rapport.

After we controlled for race/ethnicity, women undergraduate researchers reported interacting significantly less frequently with faculty mentors than men but experiencing similar levels of rapport with their faculty mentors (Figure 3 and Supplemental Table S3). Examination of the indirect model revealed a significant, indirect effect of gender on triad membership through frequency of interaction (Table 4). This indicates that, even though female undergraduate researchers reported similar levels of rapport with their faculty mentors as their male counterparts, they were more likely than men to participate in an open triad than the more beneficial closed triad (Aikens et al., 2016), due in part to interacting less frequently with faculty than did men.

After we controlled for gender, URM students interacted with faculty mentors significantly more frequently than white students but reported similar levels of rapport with their faculty mentors. Examination of the indirect model showed a significant indirect effect of being a URM student on triad membership through frequency of interaction (Table 4). This means that, even though URM and white students reported similar levels of rapport with their faculty mentors, URM students interacted more frequently with their faculty mentors than white students, which increased URM students' odds of being in the more beneficial closed triad (Aikens et al., 2016).

In contrast to women and URM students, Asian students interacted with their faculty mentors as frequently as white students but reported significantly lower rapport with their faculty mentors (after we controlled for gender). The indirect effect of being Asian on students' triad membership through rapport was significant, meaning that Asian students experienced lower rapport with their faculty mentors compared with white students, which was associated with their increased likelihood of belonging to open triads compared with closed triads. We note that

TABLE 4. Indirect effects $( \pm$ SE) for path model 1

\begin{tabular}{|c|c|c|c|c|}
\hline & \multicolumn{2}{|c|}{$\begin{array}{c}\text { Mediator: frequency } \\
\text { of interaction }\end{array}$} & \multicolumn{2}{|c|}{ Mediator: rapport } \\
\hline & $\begin{array}{c}\text { Indirect } \\
\text { effect }( \pm S E)\end{array}$ & $p$ Value & $\begin{array}{c}\text { Indirect } \\
\text { effect }( \pm S E)\end{array}$ & $p$ Value \\
\hline \multicolumn{5}{|l|}{ Gender } \\
\hline Female & $-0.358(0.118)$ & 0.002 & $-0.133(0.084)$ & 0.115 \\
\hline \multicolumn{5}{|c|}{ Race/ethnicity } \\
\hline Asian & $-0.104(0.123)$ & 0.400 & $-0.198(0.093)$ & 0.034 \\
\hline URM & $0.457(0.149)$ & 0.002 & $0.112(0.105)$ & 0.289 \\
\hline
\end{tabular}


significant indirect effects can be found without significant direct effects when the direct effects are small and when the mediator fully accounts for the association between the independent and dependent variable (LeBreton et al., 2008). Therefore, our results suggest that differences between Asian and white students' triad membership were fully accounted for by Asian-white differences in rapport.

To understand whether the small differences in triad membership experienced by women, Asian students, and URM students had a meaningful effect on their research outcomes, we examined whether the effects of students' sociodemographics on their outcomes were mediated by triad membership (Figure 4). Because we used a binary mediator, $R^{2}$ values for the regressions were not available. After we controlled for race/ethnicity, women were less likely to be in the closed triad compared with men, which could partially explain their lower scientific identity, scholarly productivity, and intentions to pursue a STEM $\mathrm{PhD}$ (Figure 4, Table 5, and Supplemental Table S4). We found significant indirect effects of gender through mentoring triad on all three outcomes. We also found a significant direct effect of gender on scholarly productivity. Men are $~ 1.4$ times more likely than women to achieve a higher level of scholarly productivity, even after differences in triad membership between men and women are taken into account. The significant indirect and direct effects of gender on scholarly productivity suggest that mentoring triad mediates part of the relationship.

After we controlled for gender, URM students were $~ 1.9$ times more likely to be in the closed triad than the open triad compared with white students, and this partially accounted for the greater outcomes that URM students reported compared with white students (Table 5). Significant indirect effects of triad membership were found for all three outcomes. Additionally, after accounting for triad membership, URM students were still 1.7 times more likely than white students to increase their intentions to pursue a STEM $\mathrm{PhD}$ as a result of the research experience. This significant direct effect indicates that other factors in addition to triad membership lead to URM students' increased intentions to pursue a STEM PhD.

After we controlled for gender, Asian students had lower scientific identity and were less likely to increase their intentions to pursue a STEM PhD after completing their research experiences than white students. This effect was not related to

TABLE 5. Indirect effects for path model $2^{\mathrm{a}}$

\begin{tabular}{lccc}
\hline & $\begin{array}{c}\text { Scientific } \\
\text { identity }\end{array}$ & $\begin{array}{c}\text { Scholarly } \\
\text { productivity }\end{array}$ & $\begin{array}{c}\text { Intentions } \\
\text { to pursue a } \\
\text { STEM PhD }\end{array}$ \\
\hline $\begin{array}{l}\text { Gender } \\
\text { Female }\end{array}$ & $-2.455^{*}$ & $-2.183^{*}$ & $-2.252^{*}$ \\
Race/ethnicity & & & \\
Asian & -1.498 & -1.415 & -1.437 \\
URM & $2.235^{*}$ & $2.019^{*}$ & $2.074^{*}$ \\
\hline
\end{tabular}

aWe used Iacobucci's (2012) method for categorical variables because we had a binary mediator and two ordinal outcomes. $z_{\text {med }}$ values are shown, which are calculated from the regression coefficients and their standard errors in the path model 2 output. $z_{\text {med }}$ is compared with that of a standard normal distribution, where a value $>|1.96|$ is considered significant (two-tailed distribution with $\alpha=0.05$ ).

"Significant indirect effect. triad membership (Table 5), which suggests that factors other than mentorship influence Asian students' outcomes.

\section{LIMITATIONS}

Longitudinal data are most appropriate for path models, whereas our path models relied on cross-sectional data. Therefore, we cannot make strong causal inferences from our data. That said, the use of gender and race/ethnicity as the first variables in the path models is appropriate, because students enter into their research experiences with these characteristics. Further, with respect to the first path model (Figure 3), it seems unlikely that students would define the triad in which they participated without considering frequency of interaction or rapport with the faculty mentor, because both variables have been found to relate to the presence or absence of ties in social networks (Granovetter, 1973; Marsden and Campbell, 1984). In the second path model (Figure 4), we cannot be sure that students' membership in open versus closed triads leads to increased outcomes or whether some other factor, such as prior research experience, leads to both triad membership and increased outcomes. A longitudinal study design would help to clarify this, for example, by collecting data on students' scientific identity before and following their research experiences.

We used three broad categories to define students' racial/ ethnic identities: white, Asian, and URM. Although this allowed us to complete a coarse-grained analysis of students' experiences in mentored research based on race/ethnicity, we recognize that there are likely important differences among racial and ethnic groups that were consolidated into the broader categories. For example, among the groups that make up our URM category, significant differences in the quality of student-faculty interactions have been found between Latino/a and Native American students (Lundberg and Schreiner, 2004). Research has also found that students in different Latino/a subgroups differ in their academic experiences and achievement (e.g., Baker et al., 2000; Nuñez and Crisp, 2012). Our race/ethnicity categories also do not distinguish among the different Asian ethnicities. Southeast Asian students, for example, are stereotyped differently than East Asian students (Museus and Park, 2015) and have different educational experiences than East Asian students (Ng et al., 2007). We also did not examine students' nations of origin or whether they were first in their families to be born in the United States. Understanding the unique influence of mentored research for students from diverse racial and ethnic groups will require disaggregating broad groups through the collection of more detailed racial and ethnic identity data from students. The U.S. Census Bureau is currently testing more refined ways of categorizing sociodemographics for the 2020 Census (U.S. Census Bureau, 2015), which could ultimately support more nuanced analyses of the experiences of diverse groups.

Our sample did not include sufficient representation of subgroups of students to examine interactions among gender, race, and ethnicity. This means that a student identifying as Latina and female would be included in the URM and female subsamples, whose results appear to be contradictory. Specifically, students who identify as women are more likely to be in open triads and realize less positive outcomes, while students who identify as URM are more likely to be in closed triads and realize more positive outcomes. In addition, our results also suggest that students who identify as men and students who 
identify as URM are both more likely to be in closed triads and realize more positive outcomes. These results raise questions regarding what patterns would be observable if the intersection of gender and race/ethnicity were addressed in the analysis, rather than gender alone or race/ethnicity alone. Future research must explicitly address intersectionality, or the interconnected nature of social identities (Crenshaw, 1989), to identify and characterize the research mentoring experiences of undergraduate students who represent unique intersections of gender, race, and ethnicity. The current data set also did not include sufficient representation of triads with a gender and race/ethnicity match (e.g., female undergraduate researchers and female faculty, URM undergraduate researchers and URM faculty) to examine whether the dynamics or outcomes of matched relationships differed from those of cross-gender or cross-cultural relationships. Future research should make special efforts to examine the experiences of gender- and race/ ethnicity-matched dyads and triads.

Our results are based on the experiences of undergraduate researchers who are mentored by both postgraduates and faculty members at research universities. Therefore, we cannot make inferences about how students' gender and race/ ethnicity relate to other types of research mentoring relationships, such as direct mentorship only by a faculty member, which is common at primarily undergraduate institutions. Future research should examine how characteristics of dyadic relationships, such as interaction frequency and relationship closeness, between undergraduate researchers and faculty mentors (i.e., no postgraduate) relate to undergraduate researchers' outcomes.

\section{DISCUSSION}

Previous research on mentoring triads demonstrated that undergraduate researchers in different types of mentoring triads realized different outcomes (Aikens et al., 2016). In particular, students in the closed triad realized more positive outcomes than students in the open triad (Aikens et al., 2016). Therefore, it is critical to determine which students participate in closed versus open triads. Our results demonstrated that women were more likely to be in open triads than in closed triads compared with men as a result of less frequent interaction with their faculty mentors. Women's lower likelihood of being in closed triads was associated with their reports of lower scientific identity, a lower likelihood of increasing their intentions to pursue a STEM PhD, and their lower scholarly productivity compared with men. In contrast, URM students reported greater frequency of interaction with their faculty mentors than white students, which in turn was related to a greater likelihood of participating in the closed triad and higher reports of scientific identity, scholarly productivity, and intentions to pursue a STEM PhD. Asian students reported lower rapport with their faculty mentors compared with white students, which in turn was associated with their greater likelihood of being in open triads. However, Asian students' reports of lower scientific identity and their lower likelihood of increasing intentions to pursue a STEM PhD were unrelated to their triad membership.

These results are somewhat surprising, given that previous studies have failed to find evidence that students of different genders or races differ in their scientific identity or intentions to pursue postgraduate education in biology or STEM after a research experience (Lopatto, 2004; Eagan et al., 2013; Robnett et al., 2015). However, these studies treat research experiences like a "black box," rather than examining student outcomes in terms of mentoring or other features of research experiences. By explicitly sampling students in two common but distinct mentoring structures, our results suggest that there may be subtle but critical differences in the outcomes undergraduates realize from research experiences that may be partly explained by differences in their interactions with their faculty mentors. Gender and race/ethnicity accounted for only a small portion of the variance in triad membership. Yet even small differences in outcomes are associated with students' long-term persistence in science (e.g., Estrada et al., 2011). In the following sections, we discuss our findings in more detail as they relate to different student groups.

\section{Mentoring Structures and Outcomes for Female Students}

Female undergraduate researchers were relatively more likely to report participating in the open triad compared with men; this association was mediated by female students' less frequent interactions with faculty. Gender was indirectly related to outcomes through triad membership; membership in the open triad was in turn associated with less scholarly productivity, lower intentions to pursue a PhD in STEM, and lower scientific identity. This contrasts with the findings of a number of studies that have found that female students interact with faculty equivalently or more than male students (Kuh and $\mathrm{Hu}$, 2001; Sax et al., 2005; Fuentes et al., 2014). Future research should explore whether differences in how often female versus male students interact with their faculty mentors can be attributed to the faculty member, the student, or a combination of the two.

Although speculative, one possible explanation is that faculty interact less frequently with female students because of factors attributable to the faculty member, such as the belief that women are less suited for STEM careers or have lower research potential. Faculty members of both genders have been shown to have unconscious biases against women in science, including rating women less deserving of mentoring than men with the same academic credentials (Moss-Racusin et al., 2012). Alternatively, female students may interact less with faculty because of factors attributable to the student. For example, compared with their male counterparts, female students may be less comfortable interacting with male faculty. Protégés in cross-gender mentoring relationships may not develop the same level of interpersonal comfort with their mentors that individuals in same-gender mentoring relationships do (Ragins, 1997; Allen et al., 2005), which could lead to less frequent interactions with a mentor. However, female and male students reported similar levels of rapport with their faculty mentors and almost half of the faculty mentors who participated in our study are women ( $n=119$ faculty mentors identified as women of $n$ $=293$ responding faculty mentors $=41 \%$ ), suggesting that a nontrivial portion of the undergraduates in our sample are likely to have been mentored by women faculty.

Sociocultural differences between men and women could also explain differences in how frequently undergraduate researchers and their faculty mentors interact. Research on gender roles has demonstrated that men are generally more 
aggressive than women (Eagly, 1987). This could result in male students initiating more interactions with faculty than female students. Female students on average have lower self-efficacy in STEM subjects than male students (Williams and George-Jackson, 2014; Wilson et al., 2015). Thus, female students may be more reluctant to initiate interactions with their research advisors. Higher self-efficacy may provide male students with the confidence to interact with faculty more frequently or to overreport interactions with a faculty mentor. To distinguish among these possibilities, future research should make use of direct observation of student-faculty interactions or measures of mentor effectiveness (Byars-Winston et al., 2015). This will help ascertain the extent to which students reliably report frequency of interactions with faculty members and understand what may count as a meaningful interaction for different students.

Undergraduates' gender also had a significant direct effect on their scholarly productivity even after taking mentoring structure into account. Specifically, women in closed triads reported lower scholarly productivity than men in closed triads, even when they reported interacting with their faculty mentors at the same level. Lower scholarly productivity in undergraduate research puts women at a competitive disadvantage for graduate school admissions or academic jobs, which counters efforts to diversify the STEM workforce. Although we took great care to frame the questions about scholarly productivity to minimize ambiguity and we tested these questions for clarity using cognitive interviews (unpublished data), it is possible that women underestimate their scholarly productivity relative to their male counterparts. Future research should aim to document scholarly productivity more directly, such as through provision of citations for scholarly work. Our results add to a growing body of literature that identifies subtle differences in the experiences of men and women at the early stages of their training in biology (Moss-Racusin et al., 2012; Eddy et al., 2014; Grunspan et al., 2016). Although the impacts of these subtle differences are unclear, the cumulative effects of such differences have the potential to deter women from pursuing careers in biology.

\section{Mentoring Structures and Outcomes of Students from URM Backgrounds}

Compared with white students, URM students were more likely to report participating in a closed triad than an open triad, a difference that was mediated by the frequency of their interactions with their faculty mentor. Although we do not have data on whether the URM students in our study participated in structured research programs, many URM students do so through programs such as the National Institutes of Health's Maximizing Access to Research Careers program (583 undergraduates in FY2016) or Research Initiative for Scientific Enhancement program (631 undergraduates in FY2016; National Institute of General Medical Sciences, 2016). Faculty mentoring is an important component of many of these programs, which may explicitly or implicitly encourage more direct interaction between URM students and their faculty mentors. Furthermore, URM students attending minority-serving institutions, such as historically Black colleges and universities (HBCUs) and Hispanic-serving institutions (HSIs), may receive more support than at predominantly white institutions (PWIs). For example, Black students at HBCUs interact more frequently with faculty than Black students at PWIs (Nelson Laird et al., 2007; Hurtado et al., 2011). Because our URM student sample contains only two students who conducted research at an HBCU, this is unlikely to be driving the pattern of student-faculty interaction that we observed. However, our URM student sample does contain a number of Latino/a students at HSIs ( $n=93$ total students identifying as Latino/a in our data set out of 138 URM students; $n=46$ students identifying as Latino/a whose college or university is classified as an HSI). Although previous research has failed to find any difference in student-faculty interactions between Latino/a students at HSIs and PWIs (Nelson Laird et al., 2007; Hurtado et al., 2011), we cannot rule out the possibility that the HSIs in our data set have created a culture that fosters student-faculty interactions or that these HSIs are home to structured mentoring programs that help ensure more positive outcomes for students. Future research should query students about their participation in structured research programs in order to examine or control for potential programmatic effects more directly.

URM students reported greater scientific identity and more scholarly productivity and were more likely to increase their intentions to pursue a $\mathrm{PhD}$ in a STEM discipline after their research experiences than white students in our sample. This difference was partially mediated by URM students' greater participation in closed mentoring triads compared with white students. It is possible that direct interaction with a faculty mentor offered access to role modeling and validation from an established scientist, which served to develop URM students' scientific identity (Cole, 2007; Hurtado et al., 2011; Syed et al., 2011), even though most of the faculty in our study were not URMs themselves ( $n=19$ identified as URM out of $n=293$ faculty $=6.5 \%$ ). Alternatively, the closed triad, which is characterized by interactions among all three members-undergraduate, postgraduate, and faculty member-may be creating a unique growth environment for students (Aikens et al., 2016). Participation in the closed triad only partially mediated URM students' increased intentions to pursue a PhD in STEM. Therefore, it is not just access to a faculty mentor that leads to differences in URM and white students' intended pursuits.

\section{Mentoring Structures and Outcomes of Asian Students}

The Asian students in our study reported lower rapport with their faculty mentors compared with white students, which was associated with their increased likelihood of participating in open triads compared with white students. Although we did not find a statistically significant relationship between Asian students and triad membership in the direct model, it is not uncommon to find a nonsignificant direct effect and a significant indirect effect with the inclusion of a mediator, if the mediator is fully explaining the relationship (LeBreton et al., 2008). Thus, our results suggest that Asian-white differences in triad membership could be completely explained by Asian students' relatively lower rapport with their faculty mentors. However, we note that these effects, although significant, are small in magnitude, and that race and gender accounted for a very small proportion of variance in rapport $\left(R^{2}=0.017\right)$. As such, Asian and white students in this study tended to report relatively similar mentoring experiences.

Asian students reported significantly lower rapport with their faculty mentors while reporting the same frequency of 
interaction as white students. This is noteworthy, given the number of studies that have found Asian students interact less frequently with faculty than white students (Kuh and $\mathrm{Hu}, 2001$; Lundberg and Schreiner, 2004; Chang, 2005). Previous research suggests many reasons that Asian undergraduate researchers might report lower rapport with their faculty members. For example, faculty may perceive Asian students as academically competent due to the "model minority" stereotype (Suzuki, 2002) and thus may offer less encouragement or guidance than they would offer to students perceived as less academically competent. Although not examined in the current study, another possibility is that Asian students experience a cultural mismatch with their faculty mentors regarding their communication styles. Asians tend to use indirect communication methods to express negative feelings in an ambiguous manner, while Europeans tend to use more direct communication methods (Gudykunst, 2001). Asian students may perceive direct feedback or feedback that is intended to be constructive as signs of disrespect or dislike by the mentor. Future research should examine the extent to which these factors (e.g., mentor perception of protégé competence, student and mentor communication style) play a role in the quality of mentoring relationships between Asian students and their faculty research mentors.

Asian students in this study reported lower scientific identity and lower scholarly productivity compared with white students, but these outcomes appear unrelated to their triad membership. To better understand the research experiences of Asian students, we examined responses to an additional item: "Compared to your intentions before doing research, how likely are you now to enroll in a science related professional degree program (e.g., medical, dental, veterinary medicine, etc.)." We conducted an ordinal regression using race as a predictor and gender as a control variable and found that Asian students were twice as likely ( $b=0.719$ (0.159), $p=0.000)$ to increase their intentions of pursuing a science professional degree compared with white students. While speculative, this suggests that the research experience per se may not be deterring Asian students from pursuing science in general; rather, it may be that this experience is increasing their interest in professional degree programs.

\section{Conclusions and Recommendations for Practice}

Taken together, our results indicate that social network theory has some explanatory power for thinking about the influence of gender and race/ethnicity on undergraduate researchers' mentoring structures and their outcomes. Frequency of interaction and rapport between undergraduate researchers and their faculty mentors accounted for a large percentage $(56.4 \%)$ of the variance in their triad memberships. Frequency of interaction also appears to be a useful and simple measure of the strength of the undergraduate-faculty tie that is empirically distinguishable from the level of rapport in their relationship. The mentoring structures and outcomes of the students in our study differed based on their gender and race/ethnicity, although the sizes of these differences were small (Cohen, 1992; Chen et al., 2010). Some of the differences in students' outcomes could be statistically explained by their mentoring structures. This suggests that students' research mentoring networks play a role in their ability to maximize the outcomes of their research experiences and that their networks differ in ways that appear to be associated with gender and race/ethnicity. The key indicator of this network difference for women and URM students was the frequency of their interaction with their faculty mentors. For Asian students, rapport was the more important indicator of their mentoring structures, but their mentoring structures did not explain differences in their outcomes. As such, Asian students' research networks as measured in our study did not appear to be associated with helping them achieve outcomes.

Our results also suggest practical ways to mentor undergraduate researchers that could improve their outcomes. First, faculty mentors could set up weekly meetings with their undergraduate researchers to ensure sufficiently frequent interactions. In our study, female students and white students, on average, reported meeting less than weekly with their faculty mentors, while male students and URM students reported meeting weekly or more than weekly, respectively. Thus, we recommend that faculty meet weekly with undergraduates to check in on their progress and provide encouragement, support, and guidance, even if undergraduates are meeting regularly with their postgraduate mentors. Second, faculty mentors should strive to develop good rapport with the undergraduate researchers in their labs, which is particularly important for the perception of a mentoring connection by Asian students. Rapport can be established by taking the time to get to know the undergraduate as a person, rather than approaching the relationship from a strictly instructional or business perspective (Schlosser et al., 2003; Handelsman, 2005).

Although our study does not yield insight into how the differences in students' mentoring structures come about, it raises the possibility of bias on the part of faculty members. Professional development programs that increase awareness of our individual biases, both explicit and implicit, and provide strategies for reducing these biases that would be beneficial for all faculty. Lessons learned from the classroom about reducing disparities can also be adapted and applied in undergraduate research experiences, such as building in structure (Freeman et al., 2011; Tanner, 2013; Eddy and Hogan, 2014). Strategies that promote structure and thus have the potential to reduce disparities in undergraduate research mentoring could include weekly meetings that focus on tracking progress, facilitating communication, and providing timely feedback, and the use of mentoring compacts or contracts such that expectations and norms are clear (University of Wisconsin Institute for Clinical and Translational Research, n.d.).

\section{ACKNOWLEDGMENTS}

Support for this work was provided by a grant from the NSF (DRL-1250917). The contents of this paper are solely the responsibility of the authors and do not necessarily represent the official views of NSF. We thank the many undergraduate research program directors and life science department heads who helped to distribute our study invitation and all of our participants for their responses. We also thank Caitlin Casey, Sarah Eddy, and the anonymous reviewers for their thoughtful comments on earlier drafts and members of the Elon University Center for Engaged Learning Research Seminar on Excellent Practices in Mentoring Undergraduate Research for their input. 


\section{REFERENCES}

Adedokun OA, Zhang D, Carleton Parker L, Bessenbacher A, Childress A Daniels Burgess W (2012). Understanding how undergraduate research experiences influence student aspirations for research careers and graduate education. J Coll Sci Teach 42, 82-90.

Aikens ML, Sadselia S, Watkins K, Evans M, Eby L, Dolan EL (2016). A social capital perspective on the mentoring of undergraduate life science researchers: an empirical study of undergraduate-postgraduate-faculty triads. CBE Life Sci Educ 15, ar16.

Allen TD, Day R, Lentz E (2005). The role of interpersonal comfort in mentoring relationships. J Career Dev 31, 155-169.

Baker BD, Keller-Wolff C, Wolf-Wendel L (2000). Two steps forward, one step back: race/ethnicity and student achievement in education policy research. Educ Policy 14, 511-529.

Barlow AEL, Villarejo M (2004). Making a difference for minorities: evaluation of an educational enrichment program. J Res Sci Teach 41, 861-881.

Becker TE, Atinc G, Breaugh JA, Carlson KD, Edwards JR, Spector PE (2016). Statistical control in correlational studies: 10 essential recommendations for organizational researchers. J Organiz Behav 37, 157-167.

Bernerth JB, Aguinis H (2016). A critical review and best-practice recommendations for control variable usage. Pers Psychol 69, 229-283.

Burt RS (2000). The network structure of social capital. Res Organ Behav 22, $345-423$.

Burt RS (2001). Structural holes versus network closure as social capital. In: Social Capital: Theory and Research, ed. N Lin, KS Cook, and RS Burt, New Brunswick, NJ: Transaction, 31-56.

Byars-Winston AM, Branchaw J, Pfund C, Leverett P, Newton J (2015). Culturally diverse undergraduate researchers' academic outcomes and perceptions of their research mentoring relationships. Int J Sci Educ 37, 2533-2554

Carlone HB, Johnson A (2007). Understanding the science experiences of successful women of color: science identity as an analytic lens. J Res Sci Teach 44, 1187-1218

Carter FD, Mandell M, Maton KI (2009). The influence of on-campus, academic year undergraduate research on STEM Ph.D. outcomes: evidence from the Meyerhoff Scholarship Program. Educ Eval Policy An 31, $441-$ 462.

Chang JC (2005). Faculty-student interaction at the community college: a focus on students of color. Res High Educ 46, 769-802.

Chemers MM, Zurbriggen EL, Syed M, Goza BK, Bearman S (2011). The role of efficacy and identity in science career commitment among underrepresented minority students. J Soc Issues 67, 469-491.

Chen H, Cohen P, Chen S (2010). How big is a big odds ratio? Interpreting the magnitudes of odds ratios in epidemiological studies. Commun Stat Simul Comput 39, 860-864.

Cheryan S, Bodenhausen GV (2000). When positive stereotypes threaten intellectual performance: the psychological hazards of "model minority" status. Psychol Sci 11, 399-402.

Cohen J (1992). A power primer. Psychol Bull 112, 155-159.

Cole D (2007). Do interracial interactions matter? An examination of student-faculty contact and intellectual self-concept. J High Educ 78, 249-281.

Coleman JS (1988). Social capital in the creation of human capital. Am J Sociol 94, S95-S120.

Crenshaw K (1989). Demarginalizing the intersection of race and sex: a black feminist critique of antidiscrimination doctrine, feminist theory and antiracist politics. Univ Chic Leg Forum 140, 139-167.

Diekman AB, Brown ER, Johnston AM, Clark EK (2010). Seeking congruity between goals and roles: a new look at why women opt out of science, technology, engineering, and mathematics careers. Psychol Sci 21, 1051-1057.

Dolan E, Johnson D (2010). The undergraduate-postgraduate-faculty triad: unique functions and tensions associated with undergraduate research experiences at research universities. CBE Life Sci Educ 9, 543-553.

Eagan MK Jr, Hurtado S, Chang MJ, Garcia GA, Herrera FA, Garibay JC (2013). Making a difference in science education: the impact of undergraduate research programs. Am Educ Res J 50, 683-713.

Eagly AH (1987). Sex Differences in Social Behavior, Hillsdale NJ: Erlbaum.
Eagly $\mathrm{AH}$, Karau SJ (2002). Role congruity theory of prejudice toward female leaders. Psychol Rev 109, 573-598.

Eddy SL, Brownell SE, Wenderoth MP (2014). Gender gaps in achievement and participation in multiple introductory biology classrooms. CBE Life Sci Educ 13, 478-492.

Eddy SL, Hogan KA (2014). Getting under the hood: how and for whom does increasing course structure work? CBE Life Sci Educ 13, 453-468.

Espinosa LL (2011). Pipelines and pathways: women of color in undergraduate STEM majors and the college experiences that contribute to persistence. Harvard Educ Rev 81, 209-240.

Estrada M, Woodcock A, Hernandez PR, Schultz PW (2011). Toward a model of social influence that explains minority student integration into the scientific community. J Educ Psychol 103, 206-222.

Freeman S, Haak D, Wenderoth MP (2011). Increased course structure improves performance in introductory biology. CBE Life Sci Educ 10, 175186.

Fuentes MV, Ruiz Alvarado A, Berdan J, DeAngelo L (2014). Mentorship matters: does early faculty contact lead to quality faculty interaction? Res High Educ 55, 288-307.

Granovetter M (1985). Economic action and social structure: the problem of embeddedness. Am J Sociol 91, 481-510.

Granovetter MS (1973). The strength of weak ties. Am J Sociol 78, 1360 1380.

Griffin KA, Gibbs KD Jr, Bennett J, Staples C, Robinson T (2015). "Respect me for my science": a Bourdieuian analysis of women scientists' interactions with faculty and socialization into science. J Women Minor Sci Eng 21 159-179.

Grunspan DZ, Eddy SL, Brownell SE, Wiggins BL, Crowe AJ, Goodreau SM (2016). Males under-estimate academic performance of their female peers in undergraduate biology classrooms. PLoS ONE 11, e0148405.

Gudykunst WB (2001). Asian American Ethnicity and Communication, Thousand Oaks, CA: Sage.

Handelsman J (2005). Entering Mentoring: A Seminar to Train a New Generation of Scientists, Madison: Board of Regents of the University of Wisconsin System.

Harsh JA, Maltese AV, Tai RH (2012). A perspective of gender differences in chemistry and physics undergraduate research experiences. J Chem Educ 89, 1364-1370.

Hathaway RS, Nagda BA, Gregerman SR (2002). The relationship of undergraduate research participation to graduate and professional education pursuit: an empirical study. J Coll Stud Dev 43, 614-631.

Hunter A-B, Laursen SL, Seymour E (2007). Becoming a scientist: the role of undergraduate research in students' cognitive, personal, and professional development. Sci Educ 91, 36-74.

Hunter A-B, Weston TJ, Laursen SL, Thiry H (2009). URSSA: evaluating student gains from undergraduate research in the sciences. 29, 15-19.

Hurtado S, Cabrera NL, Lin MH, Arellano L, Espinosa LL (2009). Diversifying science: underrepresented student experiences in structured research programs. Res High Educ 50, 189-214.

Hurtado S, Eagan MK, Tran MC, Newman CB, Chang MJ, Velasco P (2011) "We do science here": underrepresented students' interactions with faculty in different college contexts. J Soc Issues 67, 553-579.

lacobucci D (2012). Mediation analysis and categorical variables: the final frontier. J Consum Psychol 22, 582-594.

Jones MT, Barlow AEL, Villarejo M (2010). Importance of undergraduate research for minority persistence and achievement in biology. $\mathrm{J}$ High Educ 81, 82-115.

Kim YK, Chang MJ, Park JJ (2009). Engaging with faculty: examining rates, predictors, and educational effects for Asian American undergraduates. J Divers High Educ 2, 206-218.

Kim YK, Lundberg CA (2016). A structural model of the relationship between student-faculty interaction and cognitive skills development among college students. Res High Educ 57, 288-309.

Kim YK, Sax LJ (2009). Student-faculty interaction in research universities: differences by student gender, race, social class, and first-generation status. Res High Educ 50, 437-459.

Kuh GD, Hu S (2001). The effects of student-faculty interaction in the 1990s Rev High Educ 24, 309-332. 
LeBreton JM, Wu J, Bing MN (2008). The truth(s) on testing for mediation in the social and organizational sciences. In: Statistical and Methodological Myths and Urban Legends, ed. CE Lance and RJ Vandenberg, New York: Routledge, 107-141.

Lopatto D (2004). Survey of Undergraduate Research Experiences (SURE): first findings. Cell Biol Educ 3, 270-277.

Lundberg CA, Schreiner LA (2004). Quality and frequency of faculty-student interaction as predictors of learning: an analysis by student race/ethnicity. J Coll Stud Dev 45, 549-565.

MacKinnon DP (2008). Introduction to Statistical Mediation Analysis, New York: Taylor \& Francis.

Marsden PV, Campbell KE (1984). Measuring tie strength. Soc Forces 63, 482-501.

Moss-Racusin CA, Dovidio JF, Brescoll VL, Graham MJ, Handelsman J (2012). Science faculty's subtle gender biases favor male students. Proc Nat Acad Sci USA 109, 16474-16479.

Museus SD, Park JJ (2015). The continuing significance of racism in the lives of Asian American college students. J Coll Stud Dev 56, 551-569.

National Academy of Sciences, National Academy of Engineering, and Institute of Medicine (2011). Expanding Underrepresented Minority Participation: America's Science and Technology Talent at the Crossroads, Washington, DC: National Academies Press.

National Institute of General Medical Sciences (2016). Current Programs in the Division of Training, Workforce Development, and Diversity (TWD) www.nigms.nih.gov/Training/Pages/TWDPrograms.aspx (accessed 8 November 2016).

Nelson Laird TF, Bridges BK, Morelon-Quainoo CL, Williams JM, Salinas Holmes M (2007). African American and Hispanic student engagement at minority serving and predominantly white institutions. J Coll Stud Dev 48, 39-56.

Nelson DJ, Rogers DC (2003). A National Analysis of Diversity in Science and Engineering Faculties at Research Universities, National Organization for Women. http://users.nber.org/ sewp/events/2005.01.14/Bios+Links/ Krieger-rec4-Nelson+Rogers_Report.pdf (accessed 11 May 2017).

Newman DA (2014). Missing data: five practical guidelines. Organ Res Methods 17, 372-411.

Ng JC, Lee SS, Pak YK (2007). Contesting the model minority and perpetual foreigner stereotypes: a critical review of literature on Asian Americans in education. Rev Res High Educ 31, 95-130.

Nuñez A-M, Crisp G (2012). Ethnic diversity and Latino/a college access: a comparison of Mexican American and Puerto Rican beginning college students. J Divers High Educ 5, 78-95.

Ovink SM, Veazey BD (2011). More than "getting us through": a case study in cultural capital enrichment of underrepresented minority undergraduates. Res High Educ 52, 370-394.

Ragins BR (1997). Diversified mentoring relationships in organizations: a power perspective. Acad Manage Rev 22, 482-521.

Robnett RD, Chemers MM, Zurbriggen EL (2015). Longitudinal associations among undergraduates' research experience, self-efficacy, and identity. J Res Sci Teach 52, 847-867.

Sax LJ, Bryant AN, Harper CE (2005). The differential effects of student-faculty interaction on college outcomes for women and men. J Coll Stud Dev 46, 642-657.

Schlosser LZ, Gelso CJ (2001). Measuring the working alliance in advisoradvisee relationships in graduate school. J Couns Psychol 48, 157-167.
Schlosser LZ, Knox S, Moskovitz AR, Hill CE (2003). A qualitative examination of graduate advising relationships: the advisee perspective. J Couns Psychol 50, 178-188.

Schultz PW, Hernandez PR, Woodcock A, Estrada M, Chance RC, Aguilar A, Serpe RT (2011). Patching the pipeline: reducing educational disparities in the sciences through minority training programs. Educ Eval Policy An 33, 95-114.

Seymour E, Hunter A-B, Laursen SL, Deantoni T (2004). Establishing the benefits of research experiences for undergraduates in the sciences: first findings from a three-year study. Sci Educ 88, 493-534.

Smyth FL, Nosek BA (2015). On the gender-science stereotypes held by scientists: explicit accord with gender-ratios, implicit accord with scientific identity. Front Psychol 6, 415.

Snidjers TAB, Bosker RJ (1999). Multilevel Analysis: An Introduction to Basic and Advanced Multilevel Modeling, London: Sage.

Spector PE, Brannick MT (2011). Methodological urban legends: the misuse of statistical control variables. Organ Res Methods 14, 287-305.

Suzuki BH (2002). Revisiting the model minority stereotype: implications for student affairs practice and higher education. New Dir Stud Serv 2002, $21-32$.

Syed M, Azmitia M, Cooper CR (2011). Identity and academic success among underrepresented ethnic minorities: an interdisciplinary review and integration. J Soc Issues 67, 442-468.

Tanner KD (2013). Structure matters: twenty-one teaching strategies to promote student engagement and cultivate classroom equity. CBE Life Sci Educ 12, 322-331.

Thiry H, Laursen SL (2011). The role of student-advisor interactions in apprenticing undergraduate researchers into a scientific community of practice. J Sci Educ Technol 20, 771-784.

Towns MH (2010). Where are the women of color? Data on African American, Hispanic, and Native American faculty in STEM. J Coll Sci Teach 39, 6-7.

University of Wisconsin Institute for Clinical and Translational Research (n.d.). Research Mentoring. https://mentoringresources.ictr.wisc.edu (accessed 24 June 2016).

U.S. Census Bureau (2015). National Content Test. www.census.gov/programs -surveys/decennial-census/2020-census/research-testing/testing -activities/2015-census-tests/national-content-test.html (accessed 19 June 2016).

Villarejo M, Barlow AEL, Kogan D, Veazey BD, Sweeney JK (2008). Encouraging minority undergraduates to choose science careers: career paths survey results. CBE Life Sci Educ 7, 394-409.

Weston TJ, Laursen SL (2015). The Undergraduate Research Student Self-Assessment (URSSA): validation for use in program evaluation. CBE Life Sci Educ 14, ar33.

Williams MM, George-Jackson CE (2014). Using and doing science: gender, self-efficacy, and science identity of undergraduate students in STEM. J Women Minor Sci Eng 20, 99-126.

Wilson DM, Bates R, Scott E, Painter SM, Shaffer J (2015). Differences in self-efficacy among women and minorities in STEM. J Women Minor Sci Eng 21, 27-45.

Zhao C-M, Carini RM, Kuh GD (2005). Searching for the Peach Blossom Shangri-La: student engagement of men and women SMET majors. Rev High Educ 28, 503-525 